\title{
Social status determines behaviour and habitat usage in a temperate parrotfish: implications for marine reserve design
}

\author{
Pedro Afonso ${ }^{1,2, *}$, Jorge Fontes $^{1}$, Kim N. Holland $^{2}$, Ricardo S. Santos $^{1}$ \\ ${ }^{1}$ Department of Oceanography and Fisheries, University of the Azores, Cais de Santa Cruz, 9901-862 Horta, Portugal \\ ${ }^{2}$ Department of Zoology, Hawai'i Institute of Marine Biology, University of Hawai'i at Manoa, 46-007, Lilipuna Road, \\ Kane'ohe, Hawai'i 96744, USA
}

\begin{abstract}
Marine reserves should work most effectively for exploited species that are strongly site attached to small home ranges (HRs) contained within reserve boundaries. However, to benefit local fisheries through spillover, the species in the reserves must also be able to migrate to unprotected areas. We evaluated the optimal design of marine reserves for protecting and promoting spillover of a commercially important parrotfish, Sparisoma cretense (Linnaeus, 1758), by empirically quantifying short- and long-term movements of individuals originally captured inside and outside a small reserve in the Azores Islands (mid-Atlantic). Movements were quantified using active tracking, passive acoustic monitoring and standard tag-recapture. We found that the dual social organization of the species determined the individuals' movements and habitat use. Haremic fish occupied small HRs associated with permanently established male territories in high energy reef areas. Group (schooling) fish spent most of their time in sheltered reefs but expanded their HRs during the spawning season with daily migrations to the 'territorial' areas. S. cretense HR sizes were considerably larger than those previously reported for tropical parrotfishes. Passive acoustic monitoring indicated very high site fidelity and minimal dispersion for up to 30 mo. This study demonstrates that residency of adult parrotfish can last for years. Several individuals emigrated to the reserve from neighbouring areas and some of them relocated thereafter. We suggest that a network of adequately enforced marine reserves of small to medium size (ca. 1 to $5 \mathrm{~km}^{2}$ ) containing suitable habitat diversity can effectively protect core populations of $S$. cretense, but benefits to adjacent fisheries through spillover will be limited to the areas adjacent to the reserve boundaries.
\end{abstract}

KEY WORDS: Parrotfish $\cdot$ Acoustic telemetry $\cdot$ Movements $\cdot$ Home range $\cdot$ Residency $\cdot$ Marine reserves $\cdot$ Spillover

Resale or republication not permitted without written consent of the publisher

\section{INTRODUCTION}

Marine reserves (areas set aside from fishing) have been increasingly viewed as useful tools which overcome the limitations of classical methods of management, improve sustainability of local fisheries, and help to insure against population crashes and protect critical habitats (Sale et al. 2005). Well designed and enforced marine reserves should effectively protect species within reserve boundaries, leading to the socalled 'reserve effect' by which exploited species increase in number and size after protection. Effective reserves should also benefit fisheries by acting as sources of emigrant larvae or post-recruits that will replenish adjacent areas (Plan Development Team 1990). The reserve effect will be most pronounced in species which are strongly site attached and use home ranges (HRs) small enough to be contained within reserve boundaries and where resources are heavily depleted (Kramer \& Chapman 1999, Sladek-Nowlis \& Roberts 1999, Russ 2002, Halpern \& Warner 2003). There is growing empirical evidence that most reef 
fishes do in fact display such behavior (e.g. Holland et al. 1996, Samoilys 1997, Lowry \& Suthers 1998, Meyer et al. 2000, Lowe et al. 2003, Meyer \& Holland 2005). Spillover of post-recruits will, in turn, depend on the species' tendency to migrate to new areas at some point in its ontogeny, but empirical proof of spillover enhancement of fisheries is limited (Sale et al. 2005).

Parrotfishes (Scaridae) are widely distributed and exploited on tropical and subtropical reefs around the world, yet little is known about their HR sizes and movement patterns. Some studies have investigated tropical parrotfishes using visual assessment of movements and territoriality, but only over relatively short periods (e.g. Ogden \& Buckman 1973, van Rooij et al. 1996, Mumby \& Wabnitz 2002). Sparisoma cretense (Linnaeus, 1758) is the only parrotfish occurring in the Mediterranean and in the Azores, Madeira and Canaries archipelagos, and is one of only 2 parrotfishes that occupy temperate habitats. Unlike most other parrotfishes, S. cretense is sexually dimorphic but has no functional sex-change (Gonzalez et al. 1993, de Girolamo et al. 1999, Afonso et al. 2008). It lives on shallow rocky habitats and feeds mainly on algae. In the Mediterranean and the Canaries it also occupies seagrass meadows. S. cretense supports important gillnet and trap fisheries in the Atlantic archipelagos. Harvests have increased in recent years resulting in reduced abundance and size at first maturity in some exploited populations (e.g. Gonzalez \& Lozano 1992, Afonso 2002). Fishery-independent estimates indicate greater $S$. cretense abundance and size in marine reserves (Afonso 2002, Tuya et al. 2006). Therefore, it seems that $S$. cretense is a good candidate species for benefiting from protection in coastal reserves, but the exact reserve scale and spacing lacks empirical testing.

We hypothesized that habitat requirements and associated movements of Sparisoma cretense might depend on social and reproductive behaviour, which is complex and involves at least 2 alternative mating and social strategies: some males hold female harems in territories (preferably in high-energy, deeper reef areas), whereas others gather in large multi-male, mixed-sex groups (de Girolamo et al. 1999, Afonso et al. 2008). Group fish use different habitats than territorial haremic fish but may occasionally use the areas where territories dominate, ostensibly to engage in spawning events during the summer reproductive season (Afonso et al. 2008). If this holds true, group fish should show larger movements than territorial fish, especially during the reproductive season, and these behavioural characteristics would have implications for marine reserve design.

Here we present data on the short-term, seasonal and interannual movement patterns of Azorean Sparisoma cretense that elucidate these aspects of the social and reproductive behaviour and the way it influences the species' space and habitat use. We specifically tested the hypotheses that $S$. cretense (1) have small HRs, (2) are highly resident, (3) are capable of migrating and relocating and (4) have social and reproductive status that influences their movements and habitat selection.

\section{MATERIALS AND METHODS}

Study site. The study site was a $5 \mathrm{~km}$ stretch of coast in the Monte da Guia Marine Reserve (MGR) and the contiguous unprotected area outside of the Horta Harbour breakwater (HH) (Fig. 1). MGR is a semi-sunken volcano with embayments on either side located in the southeast tip of Faial Island. It is a partially protected reserve where seafood collection and recreational fishing from shore is permitted on a restricted basis, although regulations are poorly enforced (Santos et al. 1995). Spearing, netting and trapping are prohibited so parrotfish harvesting is restricted to low levels of shore angling. We concentrated on 5 areas of contrasting habitat types. Entre-Montes Bay (BEM) in the northeast corner and Porto Pim Bay (PIM) in the northwest corner are 2 sheltered, low energy habitats composed of rocky reef interspersed with sandy areas down to depths of $15 \mathrm{~m}$. Both of these areas are bounded by high-energy, structurally complex habitat (Radares [RAD] and Almeida [AL] Points, respectively) where strong tidal currents pass through vertical walls and boulder fields down to $45 \mathrm{~m}$. Finally, $\mathrm{HH}$ is of intermediate energy and structural complexity, mainly composed of boulder fields in a sandy bottom down to $30 \mathrm{~m}$.

Active tracking. We used real-time acoustic tracking to study short-term movements and quantify HR sizes for 12 fish in various parts of the study area. SCUBA divers used hand nets to capture sleeping fish in their night refuges at depths of 5 to $17 \mathrm{~m}$, and then brought them slowly (ca. $5 \mathrm{~m} \mathrm{~min}^{-1}$ ) to the surface where they were transferred to tanks containing running seawater. We inspected each fish for gas bladder overinflation and, where necessary, removed excess gas with a syringe needle inserted below the lateral line. Fish were anesthetized by immersion in a saltwater solution of MS-222 (Tricaine, $0.13 \mathrm{~g} \mathrm{l}^{-1}$ ) for 45 to $90 \mathrm{~s}$ until total loss of equilibrium and reduced opercula movements were observed. We placed each fish in a foam padded v-shaped measuring board and measured their total length to the nearest mm. Ultrasonic transmitters (V8SC-2L, Vemco) were implanted into each fish through a $2 \mathrm{~cm}$ horizontal incision in the abdominal wall at the midpoint of a line between the upper limit of the pectoral fin base and the anus. Transmitters were previously coated with a mixture of paraf- 


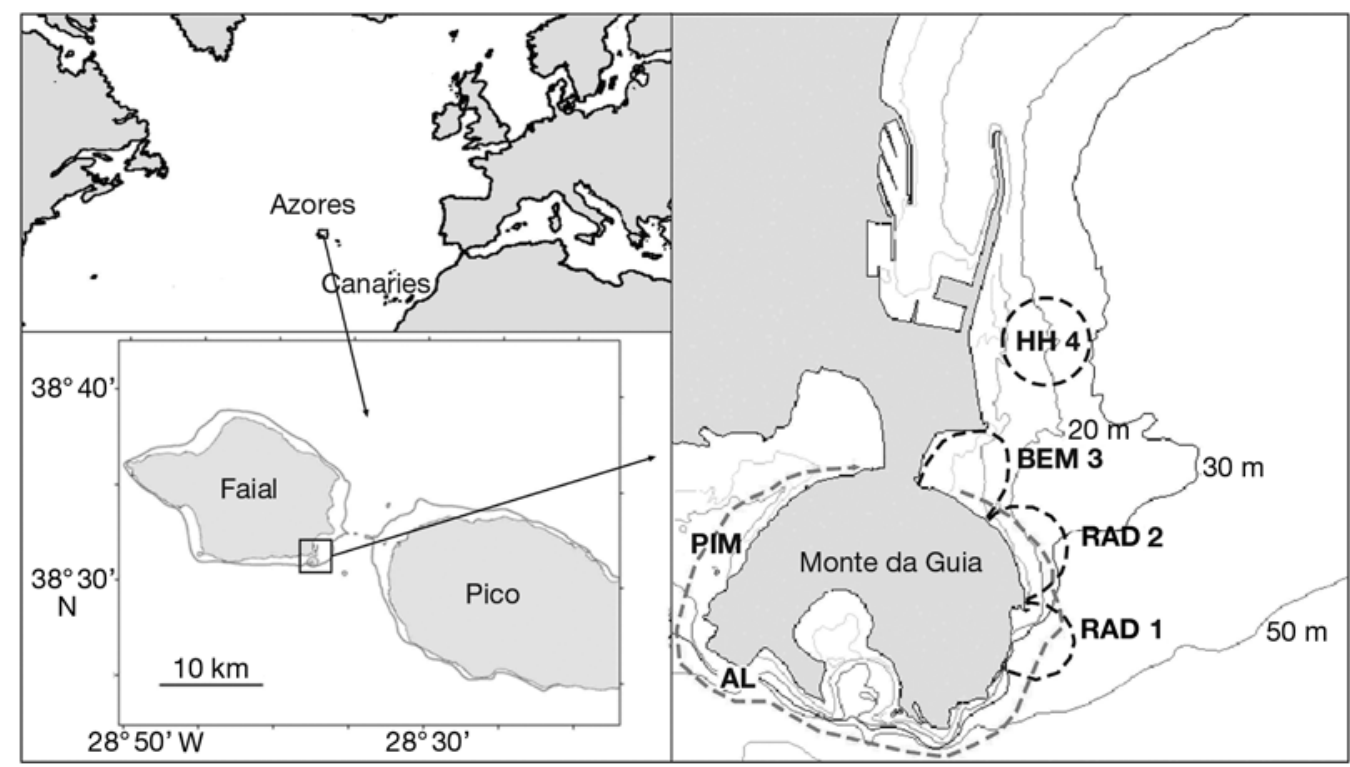

Fig. 1. The Azores in the mid-north Atlantic (upper left); the study site in the Faial-Pico channel showing the $50 \mathrm{~m}$ isobath (lower left); and a detail of the study site with sub-areas around and nearby the Monte da Guia Marine Reserve (MGR; right). (---): reserve limit; (O): estimated listening ranges of the 4 acoustic monitoring stations used in passive acoustic telemetry. Sub-areas are PIM (Porto Pim Bay), AL (Almeida Point), RAD (Radares Point), HH (Horta Harbour breakwater) and BEM (Entre-Montes Bay)

fin and beeswax and an antibiotic ointment to reduce irritation and infection. We closed the wound with surgical glue and 2 to 3 sutures ( $0.13 \mathrm{~mm}$ absorbable). We also externally tagged all fish with coloured T-type tags (Hallprint) printed with a reward notice. Fish were released in the original site of capture after a 30 to 40 min recovery period in running saltwater, and tracked using a $5 \mathrm{~m}$ semi-rigid skiff equipped with an acoustic receiver (VR60) and directional hydrophone (VH10). The receiver detects the ultrasonic acoustic ping emitted by the transmitter inside the fish every 1.5 to $2 \mathrm{~s}$. Every $15 \mathrm{~min}$ the boat was positioned to acquire the strongest possible signal from the transmitter. This position was regarded as the actual position of the fish at this time and recorded using a hand-held GPS receiver.

We tracked 5 female and 5 male Sparisoma cretense on the east side of the reserve and 1 male and 1 female on the west side (see Table 1 ). We initially tracked 2 fish continuously for $48 \mathrm{~h}$, to confirm that fish were stationary at night while sleeping, as previously indicated by extensive night diving across the archipelago by the authors, and by the fact that parrotfishes use stationary sleeping on the bottom at night (e.g. Videler et al. 1999, and references therein). Thereafter, we restricted tracking to daytime but including the $30 \mathrm{~min}$ periods prior to dawn and after dusk, which would allow us to detect the sleeping positions. Each fish was tracked on a minimum of 2 occasions throughout the 3 to $6 \mathrm{wk}$ transmitter lifespan, including a $48 \mathrm{~h}$ track in the first $4 \mathrm{~d}$ plus a $24 \mathrm{~h}$ track within 13 to $41 \mathrm{~d}$ of initial deployment. Additional opportunistic positions were acquired throughout the observation period (see Table 1). The first 6 fish were also tracked on the day after release (Day 1) to evaluate the effect of capture and handling.

We also conducted ad libitum underwater observations with SCUBA or snorkelling to ground-truth movements acquired by the tracking vessel and to relate them to behaviour and social status and habitat type. Fish were recognized by sex, external tag and surgery scar.

We calculated HR sizes from active tracking positions using kernel utilization distributions (KUD) and minimum convex polygon (MCP) areas (Kernohan et al. 2001). KUD is a probabilistic method that calculates the area of probability of finding a fish based on position data; we used $50 \%$ KUD to represent fish core centres of activity and $95 \%$ KUD to calculate the animals' HR. KUDs were calculated for each individual based on the total number of tracking positions as well as on each sub-period of tracking, i.e. a continuous tracking of at least $24 \mathrm{~h}$. Smoothing factor, a parameter selected by the user that is known to severely affect KUD calculations, was estimated by the least squares cross-validation method, as this is less affected by the number of observations (Kernohan et al. 2001). MCP, which calculates the total HR area by linking the outermost positions and producing a convex polygon that includes all positions, is a more simplistic descrip- 
tion of the animal's HR and is presented here for comparison with other works. HR and movement parameters were calculated with the Animal Movement Analyst software (Hooge \& Eichenlaub 1997) under Arcview 3.02 GIS. To test for differences and correlations between HR and fish characteristics we used Spearman rank and Mann-Whitney non-parametric tests (Zar 1999).

Passive monitoring. We used acoustic monitoring to quantify long-term site fidelity and seasonal patterns of space use in Sparisoma cretense. We implanted long-lasting coded transmitters (V8SC-2L) in 8 fish during the early spawning season in July 2003, and in an additional 2 fish in October (post-spawning) (see Table 2). Coded transmitters pseudo-randomly emitted an encoded signal on a predefined periodicity that uniquely identified each fish. We then established a permanent network of 4 underwater listening stations (VR2) to detect fish equipped with coded transmitters (Fig. 1). These stations listened for coded tags within range and logged the exact time/date and code of a given emission, and were periodically inspected for retrieval of the stored information. Range tests revealed that each of these stations could detect and log coded tags up to a distance of about $180 \mathrm{~m}$. Coded transmitters emitted signals every 30 to $90 \mathrm{~s}$ or 40 to $120 \mathrm{~s}$, which resulted in expected battery life of 335 and $465 \mathrm{~d}$, respectively, but nearly all fish emitted signals for considerably longer periods, in some cases over 30 mo (see Table 2). This deployment design allowed us to monitor the presence of tagged fish in most of the rocky habitat from the south section of RAD (Stn RAD 1) up to HH (Stn HH 4). Thus we monitored a total of $>1.5 \mathrm{~km}$ of coastline for a period of nearly $3 \mathrm{yr}$. Stations were first deployed in June 2003, except Stn $\mathrm{HH}$ 4, which was deployed in September 2003. Stn RAD 1 was removed earlier than the others (November 2004) and Stn RAD 2 suffered a short inactivity period between June and November 2004 due to flooding.

We quantified diel habitat use patterns from longterm passive monitoring data using a mean hourly presence index for each individual on each station $\left(\mathrm{I}_{\mathrm{H}}\right)$. This index corresponds to the observed average number of 'hits' per hour divided by the optimal average number based on the manufacturer's rating for a given transmitter, and assuming that a given station would log all transmissions from tagged fish within its detection range. We calculated $\mathrm{I}_{\mathrm{H}}$ for spawning (periods of 15 July to 15 September 2003 and 2005) and non-spawning seasons (1 October to 30 June).

We quantified site attachment by calculating a residency index $\left(\mathrm{I}_{\mathrm{R}}\right)$ for each fish from long-term monitoring data. $I_{R}$ was calculated as the total number of days actually detected divided by the total possible number of days (i.e. the period between the first and last day detected for that fish +1 ), and varied between 0 (no residency) and 1 (absolute residency). We calculated this index both for the whole array and also for the station where the fish was originally tagged. In the latter case, because stations had different active listening periods, we used only the total period when the station located at the tagging site was active.

Tag-recapture. To further ascertain long-term residency and possible migrations, we also conducted a limited tag-recapture program. We captured 251 fish as above, and measured and tagged them underwater with coloured T-tags before release. Fish were tagged in BEM, HH, inside the harbour and along the south shore adjacent to MGR. We used tags of different colours for each site to allow identification of the site of tagging whenever fish were visually 'recaptured' underwater. Reward announcements were posted to encourage recapture reports.

Transmitter effects and tag shedding. Ten fish were used to experimentally evaluate physiological and behavioural effects of transmitter implantation as well as to quantify ID tag shedding rates and transmitter expulsion rates. Fish were implanted with dummy transmitters using the same capture and surgery protocol, double-ID tagged and kept in a cylindrical $15 \mathrm{~m}^{2}$ cage fixed to the bottom at $20 \mathrm{~m}$ depth. They were regularly fed and monitored for $160 \mathrm{~d}$, until a storm destroyed the cage, preventing us from assessing transmitter expulsion rates.

\section{RESULTS}

\section{Transmitter effects and tag shedding}

The high success rates of both the active and passive tracking experiments and empirical observations of the fish retained within the underwater observation cage all indicate that fish quickly recovered from surgery and resumed normal swimming behaviour and habitat usage. Underwater observations of animals used for tracking showed healed incisions after $3 \mathrm{wk}$, and normal swimming and feeding behaviour was observed on the morning of Day 1 for some tracks. The shedding rate for the T-bar identification tags was $20 \%$ after $57 \mathrm{~d}$ but then remained unchanged up to $101 \mathrm{~d}$.

\section{Active tracking}

All tracked Sparisoma cretense showed diurnal activity. They would select a sleeping spot at dusk, where they remained for the night, resuming activity at dawn. Therefore, fish are assumed to be strictly 
diurnal. All tracked fish showed peak mobility at dawn and late afternoon. Early-morning mobility peaks were more pronounced during the spawning season and coincided in space and time with courtship and spawning activity of $S$. cretense observed underwater during the summers of 2002 and 2003 (see Afonso 2007 for detailed descriptions). At dusk, fish exhibited an increase in social interaction, with frequent aggressive displays and territorial males chasing conspecifics. Underwater observations showed that feeding activity occurred throughout the whole day.

HR varied widely (up to 2 orders of magnitude) among individuals but only 2 out of 12 fish used more than one core activity area (Table 1). HR size was not a function of fish size (Spearman rank: $r_{S}=0.50, p=0.1$ ), sex (Mann-Whitney $U$-test: $Z=-1.12, \mathrm{p}=0.26$ ) or reproductive season $(Z=-0.67, \mathrm{p}=0.50)$, but these relationships should be treated with caution because of reduced sample size. However, 2 different patterns of movement and space use were discernible that were related to the social strategy of individuals and to the time of the year: territorial fish had small HR and exhibited limited mobility whereas group fish had large HR and higher mobility and displayed reproductive migrations during the spawning season. For example, all 4 fish tagged in BEM during the spawning season (A1, A2, A5 and A6) undertook daily, earlymorning trips to the RAD Point area. Except for A1, these trips resulted in significant enlargement of HR (Figs. $2 \& 3$ ) for the remaining 3 fish, which were repeatedly seen grouping during the day. Male A1 was the only of these fish maintaining a territory in the bay (away from the main 'territorial' area), and one of the few fish seen doing this in the bay at all, but this was a small territory resulting in a very small core area. During those morning trips, the fish swam to RAD Point in a straight path soon after dawn and stayed there for 1 or $2 \mathrm{~h}$ before slowly returning to the bay. All underwater observations during those periods revealed that mixed sex $S$. cretense groups traveled to RAD Point at the same time. By contrast, the 2 BEM fish tracked during the winter (A11 and A12) didn't undertake such morning migrations, rather moving across their HR in a less predictable manner, and territorial fish tagged in RAD Point during the spawning season showed more limited movements. Female A8 was observed within a male harem with 2 other females and male A7 spent the daytime in a strictly territorial area.

The remaining 4 tracked fish also showed different, socially related movement patterns. Females A5 and A10 showed small HR and both resided in predominantly territorial areas. Female A10 actually moved from the group-area PIM, where it had been originally tagged, to AL Point in what could be a switch

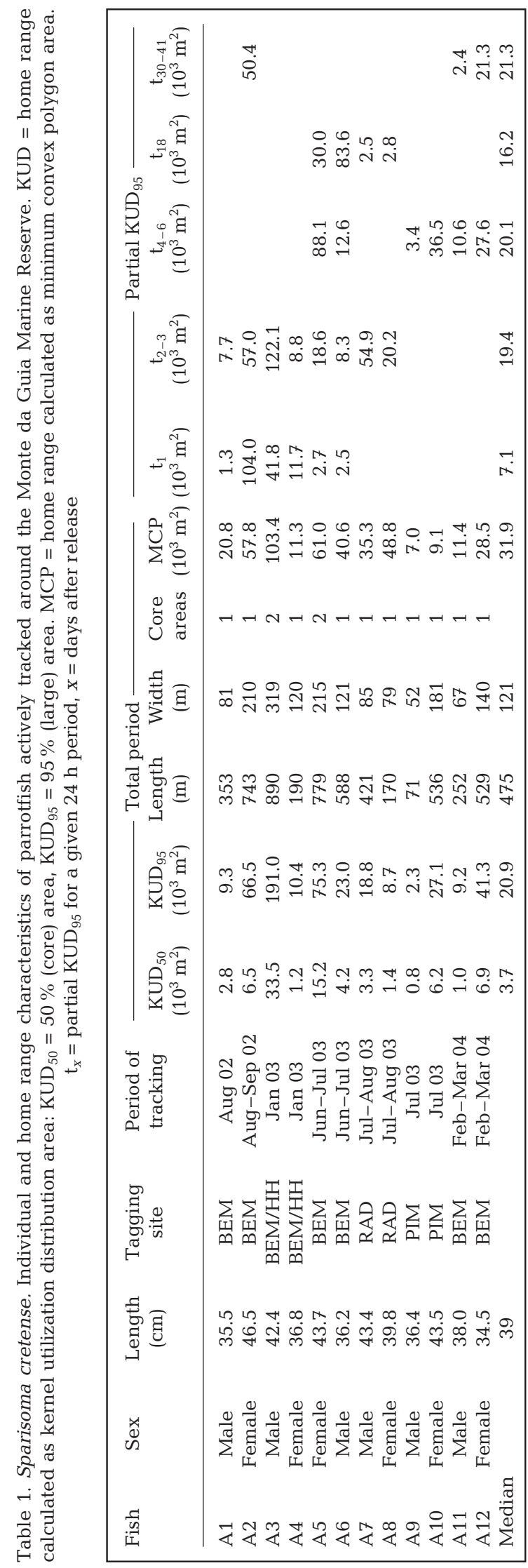


in social strategy. The fish stayed in its new location for the whole tracking period, where it was observed in a harem. Male A9 also showed small HR, but resided in PIM. Finally, male A3 displayed extensive movements throughout the day that included an outer core area at about 30 to $40 \mathrm{~m}$ in depth. This happened during the winter and we could not observe the fish underwater. Hence, the purpose of this unusual movement pattern is unclear.

Individual daily HR also varied substantially (Table 1). The most striking difference was shown by group fish A5 and A6, which were tracked 4 times within $18 \mathrm{~d}$ (Fig. 3). At the end of June (just before the onset of the spawning season), the movements of both fish were within the core area in BEM but this pattern then changed through progressive expansion and displacement towards the RAD Point area, mostly as a result of morning trips. By Day 18, both fish had core activity areas in RAD Point.

Fish movements were limited by depth and habitat type. Only 44 (4.8\%) of 923 tracking fixes occurred in depths $>30 \mathrm{~m}$ and 37 of these were accounted for by males A3 and A7, the remaining being single or 2 position fixes for another 5 fish. Only 1 fish (male A11) eventually utilized sandy substrate (3 consecutive fixes) but did not stray more than $50 \mathrm{~m}$ from the closest rocky substrate. All remaining movements occurred over hard substrate.

\section{Passive monitoring}

We detected tagged fish over periods spanning 49 to $938 \mathrm{~d}$ and only 2 fish were detected for significantly less than expected transmitter battery life (Table 2). Overall $I_{R}$ was above $75 \%$, and near $100 \%$ for most fish (Table 2). Only 1 out of 8 fish tagged in the MGR was detected outside the reserve at Stn $\mathrm{HH} 4$ (Fig. 4).

Long-term movement patterns within and around the reserve also seemed to reflect the sex and social strategies of each individual as was elucidated by active tracking. Males tagged in the RAD territorial area (P19 and P21) were highly resident (>90\% IR) at this location and made only sporadic visits to the BEM area during the non-breeding season (Fig. 4). The same general behaviour was shown by female P5, although this fish presum- ably moved out of RAD 2 to the nearby RAD 1 in the second year. These were almost certainly all territorial fish, as are the fish regularly found in that area (Afonso et al. 2008). In contrast, BEM-tagged fish used larger areas and most of them only visited the 'territorial' areas during spawning season, as exemplified by fish P3, P6 and P24. Also, female P20 used the whole RAD-BEM area (including during spawning season) as did BEM-tagged male P16. These data indicate that all these 5 fish were probably group-strategy fish, although we could only ground-truth this behaviour visually for 1 male. Finally, of the 2 fish tagged in the

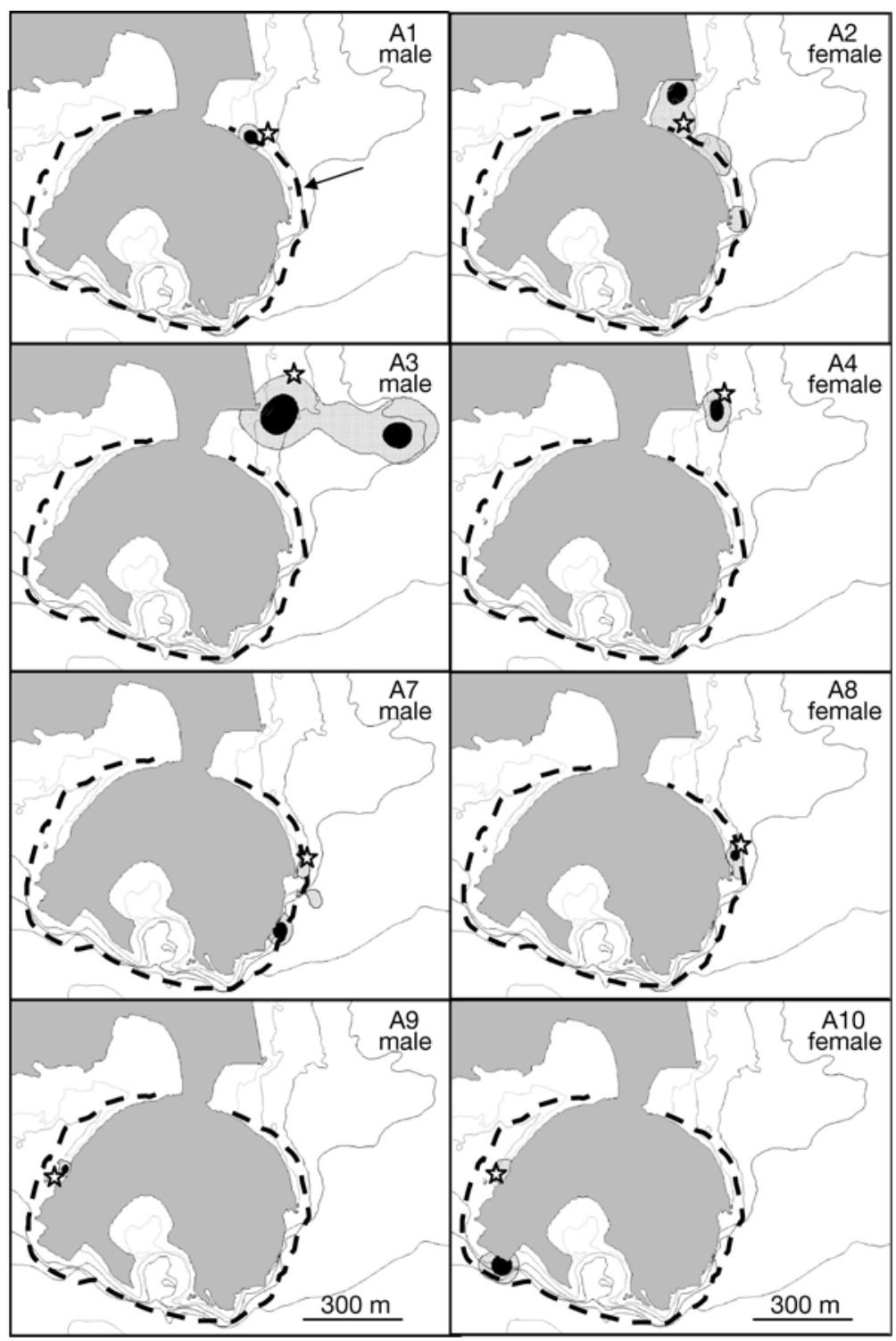

Fig. 2. Sparisoma cretense: short-term home range for 10 adult fish acoustically tracked around MGR and HH. (---): reserve limit; (O): 50\% kernel utilization distribution (KUD) of the fish's home range; (O): $95 \% \mathrm{KUD}$; ( $)$ ): original site of capture and release: Arrow in top left panel (Fish A1) indicates small home range portion resulting from early morning trips 

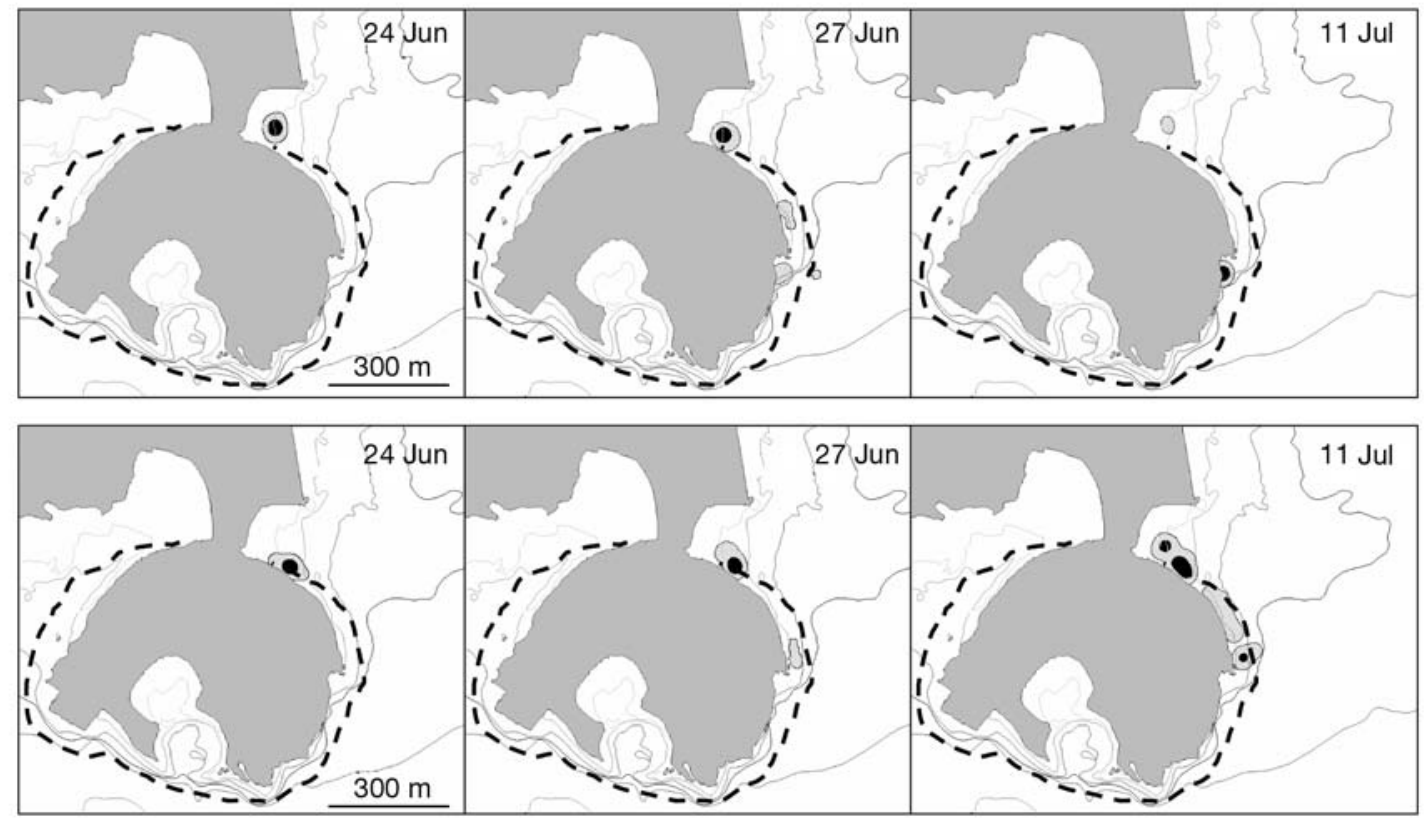

Fig. 3. Sparisoma cretense. Expansion of home range for the group-living fish male A5 (upper) and female A6 (lower) during 3 consecutive sub-periods around the onset of spawning season. (---): reserve limit; (O): $50 \%$ KUD; (O): $95 \%$ KUD

$\mathrm{HH}$ area, female P7 was highly resident at the site of tagging for over $900 \mathrm{~d}$ and male P12 relocated to the MGR right after release, apparently joining the mixedsex groups in BEM and never returning to $\mathrm{HH}$.

Patterns of diel displacements between habitats by group fish which were resident at BEM show that their visits to the RAD Point were highly clustered around the first $2 \mathrm{~h}$ of daylight during spawning season. This was not the case during non-spawning periods when displacements were random throughout the day and rarer overall (Fig. 5). Fish tagged close to RAD 1 and RAD 2 stations, including female P5, showed no clear pattern in their visits to other areas. Instead, their visits to adjacent areas were generally restricted to a few or even just one hit, most probably corresponding to short lateral displacements north of RAD that were picked up by the BEM 3 station.

\section{Tag-recapture}

ID tag recaptures confirmed the displacement patterns observed during the acoustic tracking and monitoring studies, but they also showed some potential for relocation, especially of females. Of 251 IDtagged fish, 9 (3.6\%) were recaptured and reported by fishermen. Time at liberty ranged from 25 to $210 \mathrm{~d}$ $(88 \pm 75)$. Of these 9 fish, 8 were recaptured within

Table 2. Sparisoma cretense. Individual and long-term monitoring characteristics of parrotfish passively monitored in the Monte da Guia Marine Reserve (RAD 1, RAD 2, BEM 3) and harbour breakwater (HH 4) (see Fig. 1). Expected tracking duration based on expected battery life of transmitter, as indicated by manufacturer. $\mathrm{I}_{\mathrm{R}}$ : residency index (see 'Materials and methods') calculated for the whole array and for station nearest capture site

\begin{tabular}{|c|c|c|c|c|c|c|c|c|}
\hline \multirow[t]{2}{*}{ Fish } & \multirow[t]{2}{*}{ Sex } & \multirow{2}{*}{$\begin{array}{l}\text { Length } \\
\text { (cm) }\end{array}$} & \multirow{2}{*}{$\begin{array}{l}\text { Capture } \\
\text { site }\end{array}$} & \multirow{2}{*}{$\begin{array}{c}\text { Release } \\
\text { date }\end{array}$} & \multicolumn{2}{|c|}{ Tracking duration (d) } & \multirow{2}{*}{$\overline{\text { Array }}$ I } & \multirow[b]{2}{*}{ Station } \\
\hline & & & & & Detected & Expected & & \\
\hline P19 & Male & 48.4 & RAD 1 & Jul 03 & 891 & 335 & 0.98 & $(0.56)$ \\
\hline $\mathrm{P} 20$ & Female & 37.8 & RAD 1 & Jul 03 & 366 & 335 & 1 & (1) \\
\hline P5 & Female & 36.5 & RAD 2 & Jul 03 & 934 & 465 & 0.78 & $(0.61)$ \\
\hline P21 & Male & 44.3 & RAD 2 & Jul 03 & 308 & 335 & 1 & (1) \\
\hline P3 & Female & 40.0 & BEM 3 & Jul 03 & 50 & 465 & 1 & (1) \\
\hline P6 & Female & 46.5 & BEM 3 & Jul 03 & 937 & 465 & 0.98 & $(0.98)$ \\
\hline P16 & Male & 39.5 & BEM 3 & Jul 03 & 375 & 335 & 1 & (1) \\
\hline P24 & Male & 39.0 & BEM 3 & Jul 03 & 382 & 465 & 0.99 & $(0.99)$ \\
\hline $\mathrm{P} 7$ & Female & 31.0 & HH 4 & Sep 03 & 863 & 465 & 0.86 & $(0.84)$ \\
\hline $\mathrm{P} 12$ & Male & 33.3 & $\mathrm{HH} 4$ & Sep 03 & 255 & 465 & 1 & (1) \\
\hline
\end{tabular}



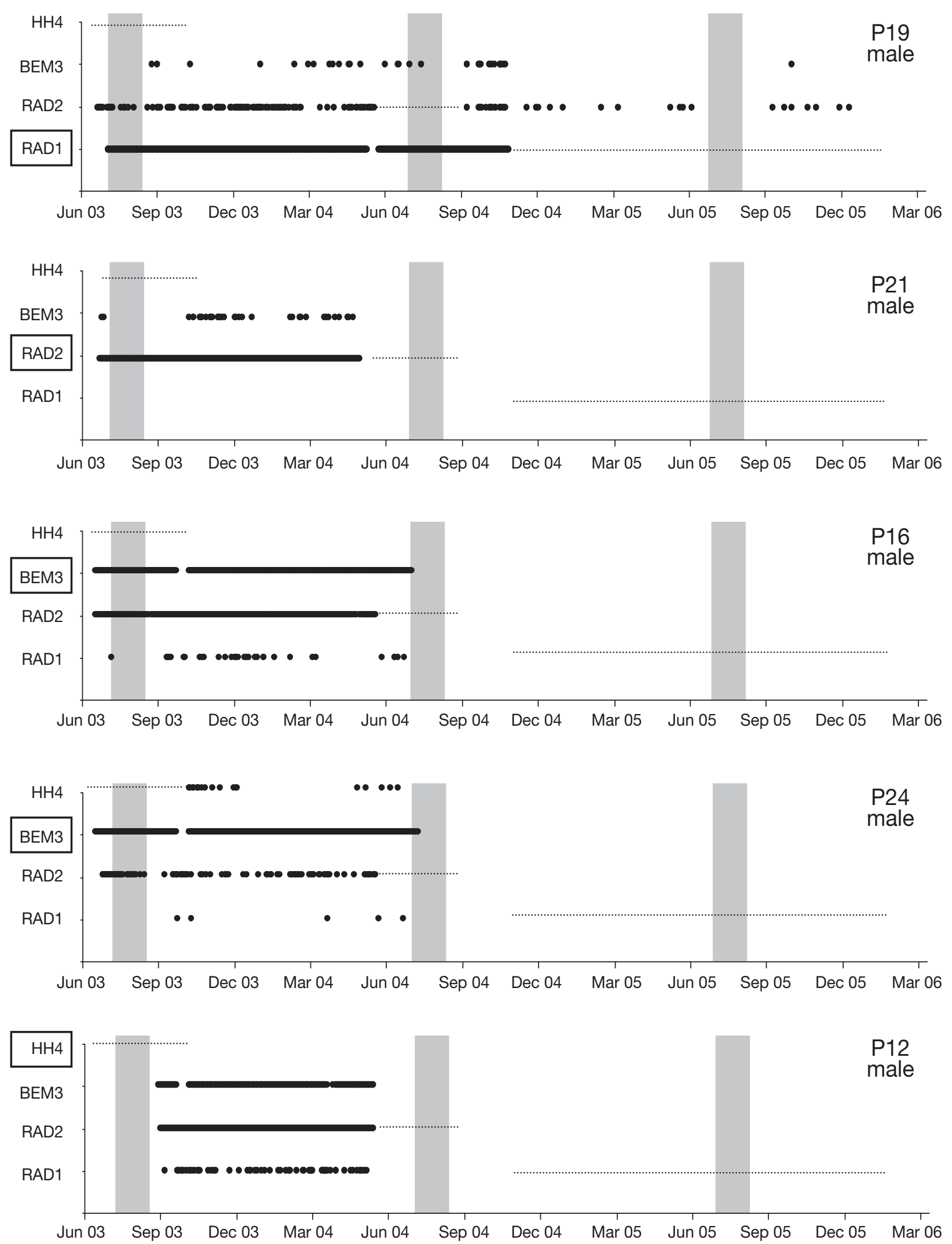

Fig. 4. Sparisoma cretense. Calendar plots (•) of individuals monitored in the 4 listening stations during the whole study period. ( $\square$ ): site of capture; (......): periods of inactivity for a given monitoring station; grey shading: spawning season. See Fig. 1 for full site names 

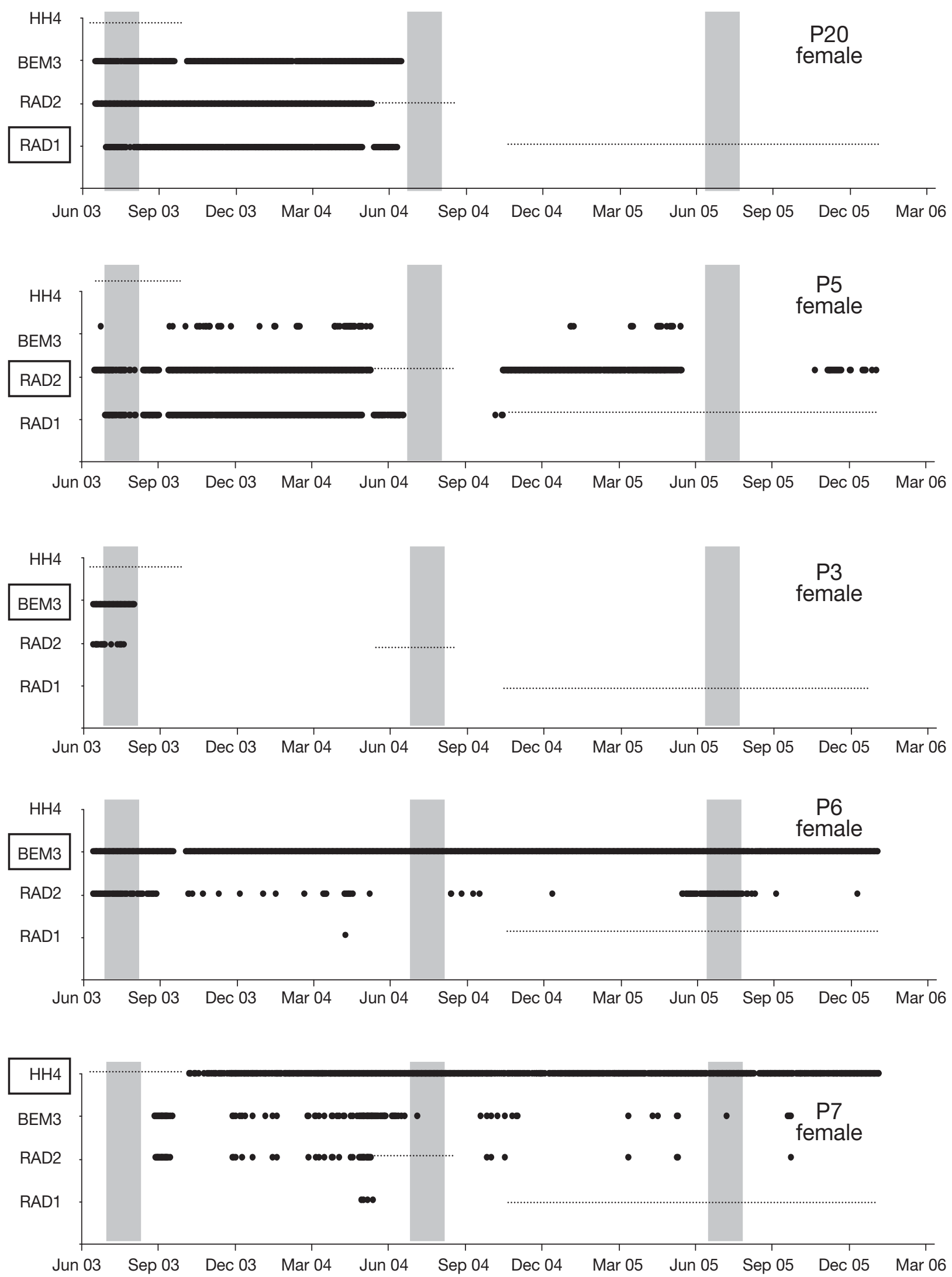

Fig. 4 (continued) 


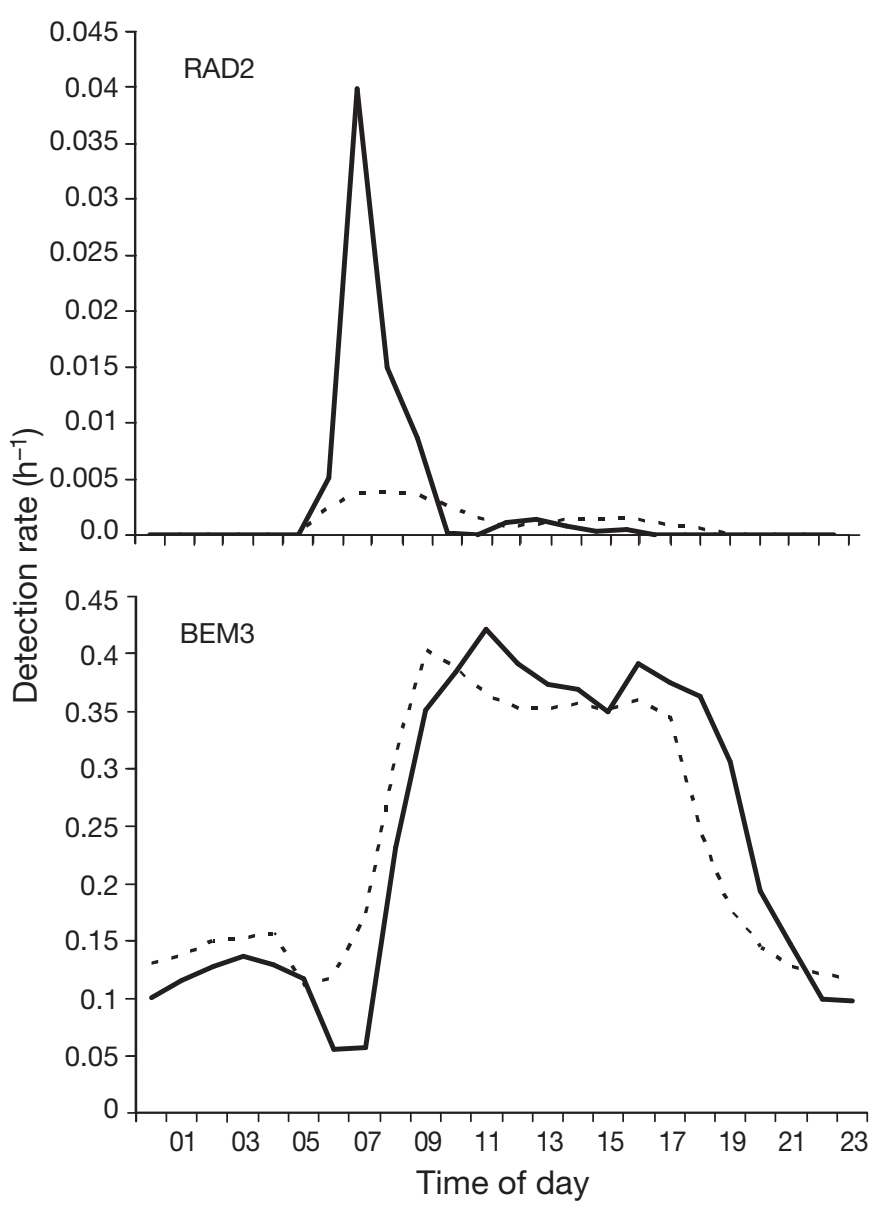

Fig. 5. Sparisoma cretense. Diel patterns of 4 group-living parrotfish detected in the monitoring stations located at BEM and RAD. (-): patterns during spawning seasons (July to

September); (---): patterns during non-spawning seasons

$150 \mathrm{~m}$ of their tagging sites, but 1 female that had been tagged in the inner harbour was recaptured in BEM (a distance of over $1800 \mathrm{~m}) 210 \mathrm{~d}$ later. Three other fish tagged in the inner harbour were repeatedly seen by divers when grouping to the north of $\mathrm{HH}$ during the day, and another (a female) was seen in BEM several weeks later. Three females tagged in BEM were repeatedly seen grouping in the bay but 3 others were re-sighted in RAD Point within a harem, several months after tagging.

\section{DISCUSSION}

\section{Home range and habitat use}

Our first hypothesis was that Sparisoma cretense would show small size HRs. Active acoustic telemetry revealed a mean $\mathrm{HR}$ size estimate of $37000 \mathrm{~m}^{2}$ for $S$. cretense, an order of magnitude larger than previ- ously reported for this species in the Mediterranean (de Girolamo et al. 1999), and for other parrotfishes in the Caribbean (e.g. Van Rooij et al. 1996, Mumby \& Wabnitz 2002). Those studies utilized diver observations to estimate $\mathrm{HR}$, and the 2 methodologies might account for considerable differences in HR size estimates, given that telemetry allows following an individual for a much longer period than diver observation. However, assuming that differences in parrotfish HR size between the Azores and elsewhere are realistic, they might reflect, besides specific differences in behaviour between species, differences in local distribution patterns of habitats critical for parrotfish or differences in forage availability among different locations. The latter explanation is supported by the fact that HRs found in this study are also one order of magnitude larger than those found in most previous telemetry studies of HR of other (non-parrotfish) demersal reef fishes from both temperate and tropical environments (Samoilys 1997, Lowry \& Suthers 1998, Meyer et al. 2000, Lowe et al. 2003, Meyer \& Holland 2005, but see Topping et al. 2005). HR size of Azorean $S$. cretense is actually more similar in magnitude to that of less site-attached species, such as Sarpa salpa (Jadot et al. 2005) and Kyphosus sectatrix (Eristhee \& Oxenford 2001).

We also hypothesised that HR and movement patterns of Sparisoma cretense would be influenced by the local social dynamics and individual status. In fact, it appears evident that differences in social behaviour explained most of the large individual variation found in HR size and habitat use. Although we could not visually confirm the social behaviour of all individuals, all those that were observed revealed the social type that would be expected based on its movement patterns, i.e. HR and daily displacements were larger for group fish compared to territorial fish.

A particularly pertinent manifestation of this difference was the daily excursion to RAD Point in the first hours of daylight shown by all BEM animals during the spawning season, which coincides in space and time with courtship and spawning activity observed by divers in that area (Afonso et al. 2008). Group fish showed an increase in this commuting behaviour as the spawning season progressed. This pattern was consistent in both actively tracked as well as passively monitored fish and repeated itself in consecutive years for the same animals. Even the HR of territorial fish reflected some early morning movements outside the territory during the spawning season, most likely related to courtship and spawning activity. For example, males A1 and A7 held territories but engaged in early morning trips to the RAD 2 area, the centre of spawning activity in the study area (Afonso et al. 2008). Hence, the movement patterns found in this study also 
support previous findings based on visual observation that group fish dominate in embayment habitats and territorial fish dominate the more exposed and deeper part of the reefs, and that the 2 social types occasionally overlap and interact as a consequence of their complex social and mating structure. This overlap is more extensive during spawning season.

\section{Residency and relocation}

All 10 coded-tag fish showed very high residency (site fidelity) during the whole passive monitoring study period regardless of transmitter lifetime, thus confirming our second hypothesis that, as adults, this species is highly site attached. In addition to the prolonged electronic detection range of fish tagged within the reserve, no detections were made by 3 additional listening stations located beyond the limits of the reserve area. We detected short periods of absence in a few animals, most possibly corresponding to temporary emigrations beyond the detection of monitoring stations. For example, female P5 was absent on $22 \%$ of the days during which it was monitored, when it probably moved to the area contiguous to RAD 1 during the 2005 spawning season. Therefore, none of the fish permanently abandoned the study area during the monitoring period. Strong site attachment of parrotfishes has been previously hypothesized based on indirect evidence from a few tag-recapture studies for several tropical parrotfish species in coral reefs of Kenya (Kaunda-Arara \& Rose 2004) and the Caribbean (Ogden \& Buckman 1973, Chapman \& Kramer 2000). However, the present study is the first to demonstrate that residency of parrotfish can last for years, even for fish that are not territorial and that make relatively large daily migrations.

Social dynamics and competition for spawning habitat also appear to explain the patterns of relocation among Azorean populations of Sparisoma cretense. Individuals can be expected to relocate after dispersal if local conditions improve net gain in fitness, either because of lower predation risk, lower competition pressure, better feeding resources or increased access to mating opportunities (Kramer \& Chapman 1999). The haremic territorial system of $S$. cretense is based on access to high quality mating sites located in highenergy, deeper reefs, and group fish most likely seek opportunities to increase their mating success by switching social modes and taking over male territories (males) or becoming haremic (females) whenever the opportunity arises (Afonso et al. 2008). Based on the fact that territorial males are typically larger than group males, and that high-quality territories located in high-energy, deeper reefs are dominated by males larger than those occupying shallower territories, we suggested that this social plasticity is governed by male-male competition (Afonso et al. 2008). Our results in this study support this hypothesis. Fish A1, for example, held a small territory in a shallow area dominated by group fish, but would engage in daily spawning migrations to the RAD territorial area during reproduction. Male $\mathrm{P} 12$ was tagged in $\mathrm{HH}$ but moved to BEM about $700 \mathrm{~m}$ away. These were both small males. Several ID-tagged females that were observed grouping travelled at least $1.5 \mathrm{~km}$ from the inside of the harbour to BEM where they were re-sighted or recaptured a few weeks or months later, and others were visually confirmed to switch from group mode in BEM to haremic mode in RAD. Patterns of withinhabitat movements related to social dynamics and mating opportunities (as well as daily foraging migrations) have also been reported for a variety of tropical parrotfishes with complex social systems (e.g. Ogden \& Buckman 1973, van Rooij et al. 1996, Mumby \& Wabnitz 2002). Therefore, density-dependent processes related to the access to vital resources seem to play a major role promoting relocation of individual $S$. cretense.

\section{Implications for the design and functioning of marine reserves}

If Sparisoma cretense is highly resident and uses HRs small enough to be contained within reserve borders, as our results indicate, then even small reserves of $1 \mathrm{~km}^{2}$ can effectively protect small core subpopulations of this species. Reserves should also include connected habitat appropriate for both social modes. Reef ledges in high-energy, deeper bottoms have a particularly important role as spawning areas for both social modes, but group fish clearly use shallower habitats for most of the time (de Girolamo et al. 1999, Afonso et al. 2008). Additionally, movements of group fish between these 2 habitats are kept within rocky habitat corridors. Accordingly, we never saw $S$. cretense over sandy bottom plains during $10 \mathrm{yr}$ of extensive diving throughout the archipelago. Therefore, marine reserves should also include at least the 2 types of rocky habitats and respective connecting corridors if they are to promote sexual interaction and reproductive success.

Habitat connectivity becomes crucial when one predicts benefits of reserves to adjacent fisheries through spillover. There was some indication from our long-term acoustic monitoring and tag-recapture data that short displacements can actually lead to relocation of individuals. This should be more evident in areas of pronounced density gradient, for example if density is 
substantially higher inside reserves than in neighbouring fishery-depleted areas, because relocation can facilitate access to high quality territories in the fished areas. However, we anticipate that spillover of adult Sparisoma cretense will be limited in range and minimal at the population level because the extension of the movements leading to relocation was reduced. Consequently, adult spillover will not be a major source of replenishment for neighbouring fishing grounds and will be restricted to the areas close to the reserve borders, as predicted by theory for fish displaying this kind of post-recruitment dispersion (Kramer \& Chapman 1999, Russ 2002, Halpern \& Warner 2003).

Instead, the benefit to adjacent fisheries by larval subsidy should be of much higher impact for local populations of Sparisoma cretense, if spawning stocks and adequate spawning habitats are effectively protected. This hypothesis is supported by the evidence that (1) local reproductive activity is highly clustered in such spawning habitats (de Girolamo et al. 1999, Afonso et al. 2008); (2) S. cretense populations within reserves are larger and hold larger numbers of large size adults than unprotected populations (Afonso 2002, Tuya et al. 2006); and (3) fecundity of large females (more common in marine reserves) is substantially higher than that of smaller females (Gonzalez et al. 1993). These evidences will all reinforce the relative importance of protected sub-populations for the reproductive potential of local populations.

In conclusion, a network of adequately enforced reserves of small to medium size $\left(1\right.$ to $\left.10 \mathrm{~km}^{2}\right)$ can protect core subpopulations of Sparisoma cretense if they include suitable habitat and migrating corridors. Benefit to adjacent fisheries through spillover is predicted to be small whereas benefit through larval subsidy can be high given the higher fecundity of individuals within reserves. Because the production of gametes seems to be the greatest advantage of marine protected areas for S. cretense, particular emphasis should be placed on identifying and protecting the traditional spawning sites that are central to the reproductive strategy of this species.

Acknowledgements. We sincerely thank A. Donnay, P. Martins, R. Prieto, M. Santos, N. Serpa, A. Rosa, V. Rosa and other volunteers for help with data collection, and C. Meyer, J. Stimson, J. D. Parrish, B. Bowen, and 4 anonymous reviewers for improvements in earlier versions of the manuscript. For individual support P.A. thanks the Portuguese Science Foundation (FCT/MCTES) (SFRH/BD/ 11132/2002), Fundação Luso-Americana (FLAD) and the Fulbright Commission; and J.F. thanks FCT/MCTES (SFRH/BD/ 12788/2003). IMAR-DOP is Research \& Development Unit \#531 funded through the Programmatic and Pluriannual programs of FCT/MCTES and Azorean Regional Science \& Technology Foundation, part of FEDER. This paper is a con- tribution to the CLIPE project (FCT/PRAXIS-XXI/3/3.2/EMG/ 1957/95), MAREFISH project (FCT-POCTI/BSE/41207/2001) and the MarBEF EU Network of Excellence (EC contribution no. GOCE-CT-2003-505446).

\section{LITERATURE CITED}

Afonso P (2002) Spatial patterns in the littoral fish community of the Azores. MS thesis, University of Coimbra

Afonso P, Morato T, Santos RSS (2008) Spatial patterns in reproductive traits of the temperate parrotfish Sparisoma cretense. Fish Res 90:92-99

Chapman MR, Kramer DL (2000) Movements of fishes within and among fringing coral reefs in Barbados. Environ Biol Fishes 57:11-24

de Girolamo M, Scaggiante M, Rasotto MB (1999) Social organization and sexual pattern in the Mediterranean parrotfish Sparisoma cretense (Teleostei: Scaridae). Mar Biol 135: $353-360$

Eristhee N, Oxenford HA (2001) Home range size and use of space by Bermuda chub Kyphosus sectatrix (L.) in two marine reserves in the Soufriere Marine Management Area, St Lucia, West Indies. J Fish Biol 59:129-151

Gonzalez JA, Lozano IJ (1992) Determinación de curvas de madurez sexual en la vieja, Sparisoma (Euscarus) cretense (L.) (Osteichthyes, Scaridae), de Canarias = Detemination of sexual maturity curves of the parrotfish, Sparisoma (Euscarus) cretense (L.) (Osteichthyes, Scaridae), off the Canary Islands. Bol Inst Esp Oceanogr 8(2):271-297

Gonzalez JA, Lozano IJ, Hernandez-Cruz CM (1993) Fecundity of Sparisoma (Euscarus) cretense (L.) (Osteichthyes, Scaridae) in the Canary Islands. Bol Inst Esp Oceanogr 9: 123-131

Halpern BS, Warner RR (2003) Matching marine reserve design to reserve objectives. Proc R Soc Lond B 270:1871-1878

Holland KN, Lowe CG, Wetherbee BM (1996) Movement and dispersal patterns of the blue trevally (Carax melampygus) in a fisheries conservation zone. Fish Res 25:279-292

Hooge PN, Eichenlaub B (1997) Animal movement extension to Arcview v.1.1. Alaska Science Center, Biological Science Office, US Geological Survey, Anchorage, AK

Jadot C, Donnay A, Acolas ML, Cornet Y, Bégout Anras ML (2005) Activity patterns, home-range size, and habitat utilization of Sarpa salpa (Teleostei: Sparidae) in the Mediterranean Sea. ICES J Mar Sci 63(1):128-139

Kaunda-Arara B, Rose GA (2004) Out-migration of tagged fishes from marine reef national parks to fisheries in coastal Kenya. Environ Biol Fishes 70:363-372

Kernohan BJ, Gitzen RA, Millspaugh JJ (2001) Analysis of animal space use and movements. In: Millspaugh JJ, Marzluff JM (eds) Radio tracking of animal populations. Academic Press, San Diego, CA, p 126-168

> Kramer DL, Chapman MR (1999) Implications of fish home range size and relocation for marine reserve function. Environ Biol Fishes 55:65-79

- Lowe CG, Topping DT, Cartamil DP, Papastamatiou YP (2003) Movement patterns, home range, and habitat utilization of adult kelp bass Paralabrax clathratus in a temperate notake marine reserve. Mar Ecol Prog Ser 256:205-216

> Lowry MB, Suthers IM (1998) Home range, activity and distribution patterns of a temperate rocky-reef fish, Cheilodactylus fuscus. Mar Biol 132:569-578

> Meyer CG, Holland KN (2005) Movement patterns, home range size and habitat utilization of the bluespine unicornfish, Naso unicornis (Acanthuridae) in a Hawaiian marine reserve. Environ Biol Fishes 73:201-210 
Meyer C, Holland KN, Wetherbee BM, Lowe CG (2000) Movement patterns, habitat utilization, home range size and site fidelity of whitesaddle goatfish, Parupeneus porphyreus, in a marine reserve. Environ Biol Fishes 59: 235-242

Mumby PJ, Wabnitz CCC (2002) Spatial patterns of aggression, territory size, and harem size in five sympatric Caribbean parrotfish species. Environ Biol Fishes 63:265-279

Ogden JC, Buckman NS (1973) Movements, foraging groups, and diurnal migrations of the striped parrotfish Scarus croicensis Bloch (Scaridae). Ecology 54:589-596

Plan Development Team (1990) The potential of marine fishery reserves for reef fish management in the U.S. Southern Atlantic. NOAA Tech Mem NMFS-SEFC-261, Washington, DC

Russ GR (2002) Yet another review of marine reserves as reef fishery management tools. In: Sale P (ed) Coral reef fishes: dynamics and diversity in a complex ecosystem. Academic Press, San Diego, CA, p 421-443

Sale PF, Cowen RK, Danilowicz BS, Jones GP and others (2005) Critical science gaps impede use of no-take fishery reserves. Trends Ecol Evol 20:74-80

Samoilys MA (1997) Movement in a large predatory fish: coral trout, Plectropomus leopardus (Pisces: Serranidae), on

Editorial responsibility: Otto Kinne,

Oldendorf/Luhe, Germany
Heron Reef, Australia. Coral Reefs 16:151-158

Santos RS, Hawkins S, Monteiro LR, Alves M, Isidro EJ (1995) Marine research, resources and conservation in the Azores. Aquat Conserv 5:311-354

Sladek-Nowlis J, Roberts CM (1999) Fisheries benefits and optimal design of marine reserves. Fish Bull 97:604-616

Topping DT, Lowe CJ, Caselle JE (2005) Home range and habitat utilization of adult California sheephead (Semicossyphus pulcher) in a temperate no-take marine reserve. Mar Biol 147:301-311

Tuya F, Ortega-Borges L, Sanchez-Jerez P, Haroun RJ (2006) Effect of fishing pressure on the spatio-temporal variability of the parrotfish, Sparisoma cretense (Pisces: Scaridae), across the Canarian Archipelago (eastern Atlantic). Fish Res 77:24-33

van Rooij JM, Kroon FJ, Videler JJ (1996) The social and mating system of the herbivorous reef fish Sparisoma viride: one-male versus multi-male groups. Environ Biol Fishes 47:353-378

Videler H, Geertjes GJ, Videler JJ (1999) Biochemical characteristics and antibiotic properties of the mucous envelope of the queen parrotfish. J Fish Biol 54:1124-1127

Zar (1999) Biostatistical analysis, 4th edn. Prentice Hall, Upper Saddle River, NJ

Submitted: January 4, 2007; Accepted: October 4, 2007 Proofs received from author(s): April 5, 2008 